\title{
Unusual Presentation of Lacrimal Gland Pleomorphic Adenoma
}

\author{
Shailesh Mani Pokharel, ' Badri Prasad Badhu, ${ }^{1}$ Punam Lavaju, ${ }^{1}$ Bhuwan Govinda Shrestha, ${ }^{1}$ Ashish Raj Pant, \\ Meenu Agarwal ${ }^{2}$ \\ 'Department of Ophthalmology, B P Koirala Institute of Health Sciences, Dharan, ${ }^{2}$ Department of Pathology, B P Koirala \\ Institute of Health Sciences, Dharan, Nepal.
}

\begin{abstract}
The pleomorphic adenoma of lacrimal gland presents as a painless, progressive, slowly growing supero-temporal swelling with variable proptosis. This tumor is usually found in adults and extremely rare in teenage. We report a case of a 15-year-old boy with pleomorphic adenoma of lacrimal gland which mimicked pseudotumor of orbit due to its presentation as an orbital inflammatory disease and the age distribution. Neuroimaging also suggested pseudotumor and oral steroid was started. But, there was no improvement on steroids and ultrasound guided Fine Needle Aspiration Cytology (FNAC) was performed which suggested Pleomorphic adenoma of the lacrimal gland. En-bloc excision of the mass through antero-lateral orbitotomy was done with satisfactory final outcome The histopathological evaluation was consistent with pleomorphic adenoma of the lacrimal gland.
\end{abstract}

Keywords: lacrimal gland pleomorphic adenoma; orbitotomy; proptosis; pseudotumor.

\section{INTRODUCTION}

Lacrimal gland lesions represent five percent to $35 \%$ of orbital tumors. ${ }^{1}$ Pleomorphic adenoma is the most common epithelial tumor of the lacrimal gland which mainly presents as a slow growing, painless enlargement of the lateral portion of upper eyelid. ${ }^{2}$ The occurrence ranges from the third to the seventh decades of life and the mean age of presentation has been reported to be 39 years. ${ }^{3}$ It is extremely rare in children. ${ }^{4} \mathrm{~A}$ case of pleomorphic adenoma of lacrimal gland which mimicked inflammatory lesion in a teenager is reported here along with its surgical management and histopathological correlation.

\section{CASE REPORT}

A 15-year-old boy presented with proptosis of right eye for the duration of three months and diminution of vision for two months. The proptosis was painful and progressive. Diminution of vision was insidious in onset and progressively worsening. There was no history of constitutional symptoms or trauma.
Examination revealed the best corrected visual acuity of $4 / 60$ in the right eye and 6/6 unaided in the left. The significant findings on the right side included diffuse swelling of the right upper eyelid with retraction of the eyelids. A firm in consistency, tender, non-reducible mass of size approximately $20 \times 10 \mathrm{~mm}$ was palpable in the right superior orbit, the posterior extension of the mass could not be appreciated (Figure 1). The proptosis measured using the Hertel's exophthalmometer showed the reading of $26 \mathrm{~mm}$ on the right side and $18 \mathrm{~mm}$ on the left. The right globe was displaced inferiorly. Superficial punctuate keratitis was present in the inferior cornea. There was relative afferent pupillary defect (RAPD) in the right eye. There was temporal pallor of the disc along with tortuosity of retinal vessels and macular edema. The intraocular pressure of the right eye was $15 \mathrm{mmHg}$ which increased to $26 \mathrm{mmHg}$ on upgaze. The left eye was normal.

Correspondence: Dr. Shailesh Mani Pokharel, Department of Ophthalmology, B P Koirala Institute of Health Sciences, Dharan, Nepal. Email: pokharelshailesh@gmail.com, Phone: +977-9852028791. 


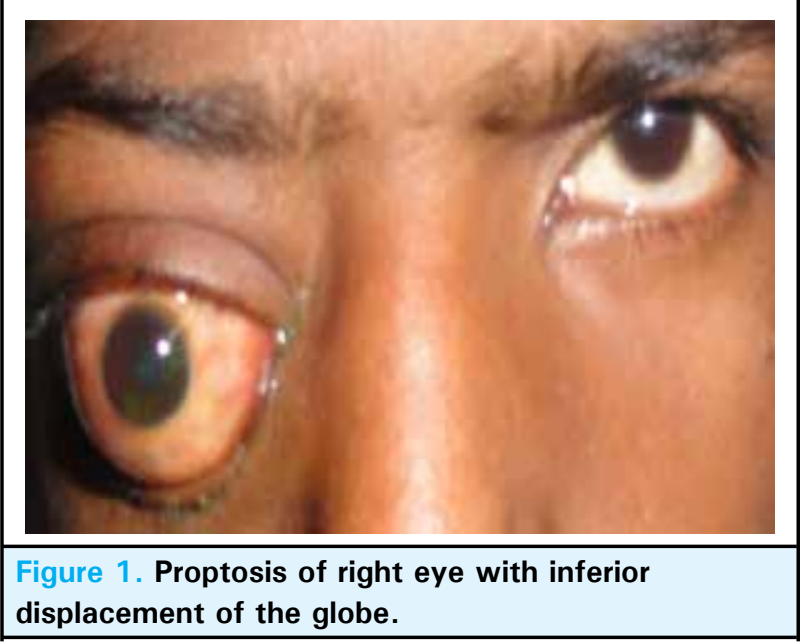

The orbital CT scan (Figure 2) revealed a well-defined homogenously enhancing hyperdense soft tissue lesion measuring $25 \times 24 \mathrm{~mm}$ in size in the retrobulbar region of the right orbit with involvement of the extraocular muscle and optic nerve sheath complex with proptosis of the right globe without bone destruction. The findings were suggestive of pseudotumor of right orbit with a differential diagnosis of optic nerve sheath tumor. The patient was initially treated with oral steroids $11 \mathrm{mg} /$ $\mathrm{kg}$ ) for the presumed diagnosis of pseudotumor of the right orbit. After a week there was no improvement. Subsequently the patient underwent ultrasound guided fine needle aspiration cytology (FNAC) of the right orbital mass. The FNAC revealed benign mixed tumor of the lacrimal gland.

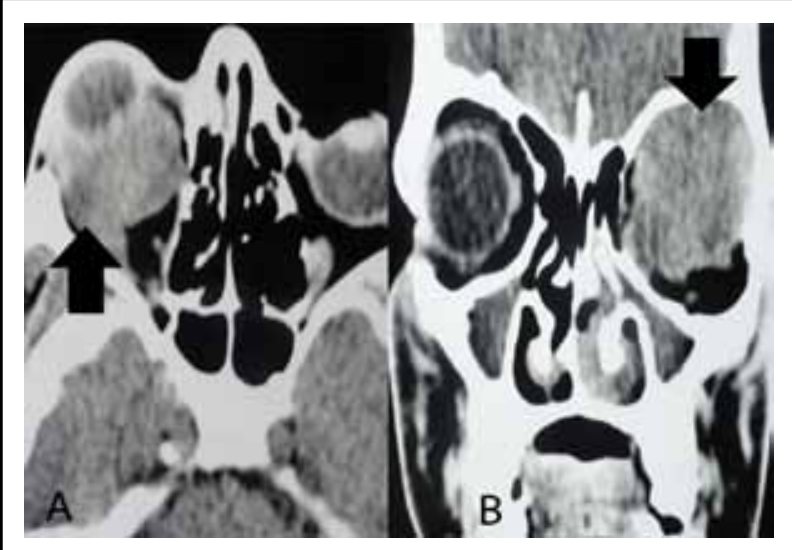

Figure 2. CT scans of the right orbit - axial (A) and coronal (B) views showing hyperdense soft tissue mass (arrowhead).

En bloc excision of the mass was performed through antero-lateral transperiosteal orbitotomy (Figure 3). Right anterolateral skin incision was made along the hairline (Fig 3a) followed by a blunt dissection and separation of muscles (Fig $3 \mathrm{~b}$ ). The bony periosteum was exposed and zygomatico-frontal suture landmark was identified (Fig 3c). A fragment of the bone was removed using a saw and a bone punch was applied on either side of the zygomatico-frontal suture and bone chip was separated (Fig 3d). The underlying mass was identified and separated from adjacent structures and removed (Fig 3e). The cut chip of bone was replaced and stabilized with bone wax and the skin was closed after putting a penrose drain (Fig 3f).

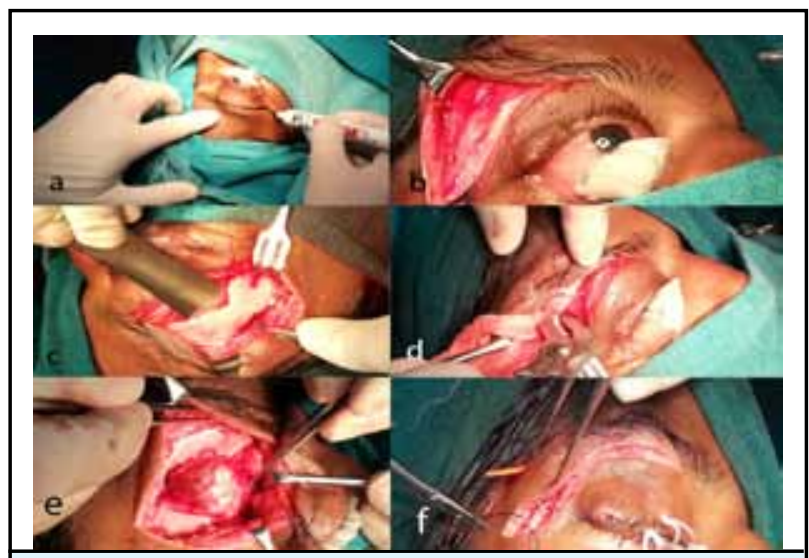

Figure 3. Surgical steps of right anterolateral transperiosteal orbitotomy (a- Marking the skin incision, b- Blunt dissection, c- Exposing bony periosteum, d-Separating bone chip, e- Identification of the mass, $f$-Skin closure with drain).

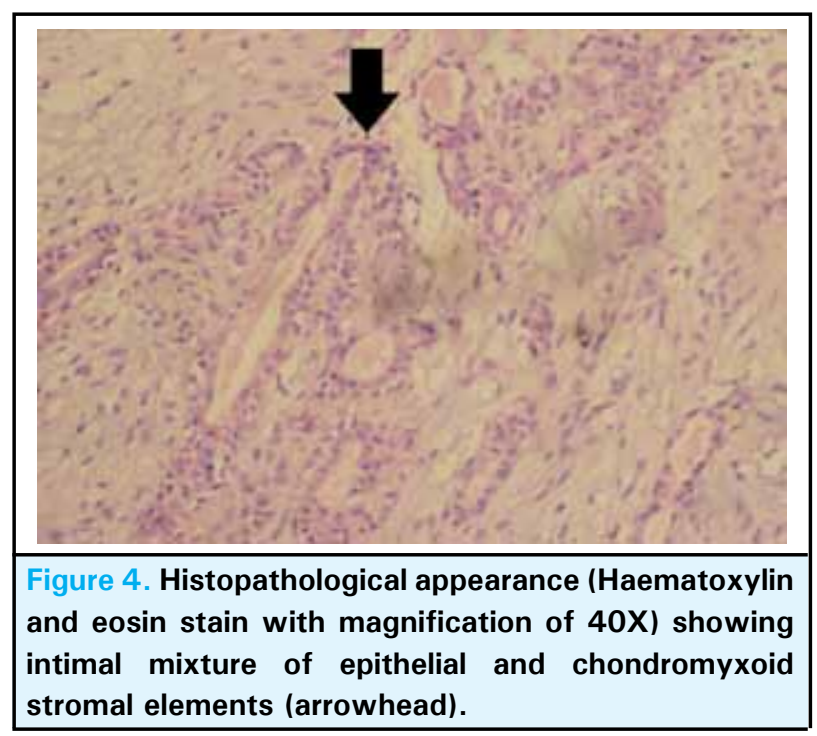

The mass was subjected to histopathological examination which demonstrated intimal mixture of epithelial and chondromyxoid stromal elements suggestive of pleomorphic adenoma of the lacrimal gland (Figure 4).

At four weeks of follow-up the best corrected visual acuity in the right eye was $4 / 60$. There was resolution 
in the amount of proptosis with improvement in extra ocular movement (Figure 5).

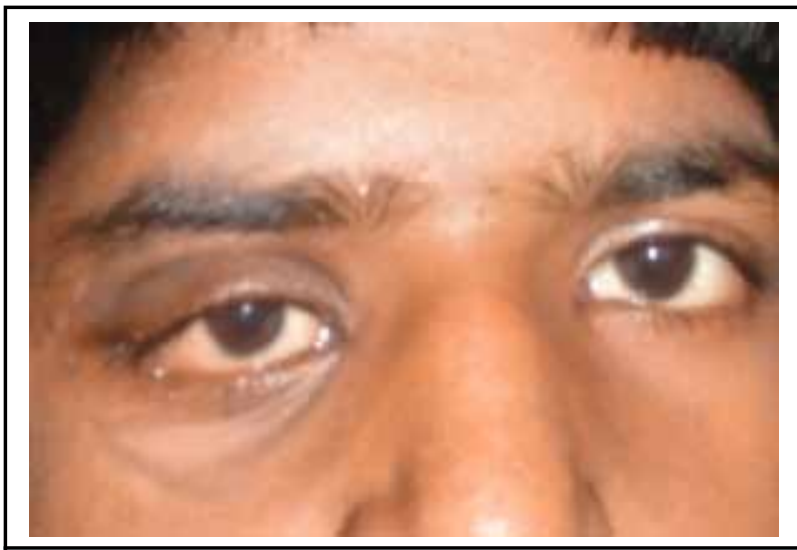

Figure 4. Picture of the patient at 4th postoperative week showing resolution in proptosis.

\section{DISCUSSION}

The typical age of presentation of pleomorphic adenoma is middle age. It rarely occurs in the adolescents. Vagefi MR et al reported cases of pleomorphic adenoma of lacrimal gland presenting atypically as an orbital inflammation mimicking orbital cellulitis, a painful subcutaneous nodule, and other demonstrating calcification and bony erosion on orbital imaging. ${ }^{5}$ In our case, the patient presented with painful proptosis mimicking pseudotumor.
The localization of the rapidly progressive painful mass of the superior orbit with the radiological findings suggestive of pseudotumor led to the treatment with steroids. As there was no improvement seen with this treatment, FNAC of the mass was performed. FNAC differentiates various pathologies of the lacrimal gland as well as prevents incomplete excision of a malignant lesion and future recurrences. Though FNAC of pleomorphic adenoma is not generally advised due to the fear of spread of the tumor cells, it aided to establish the diagnosis in this case. Verma and Kapila demonstrated FNAC of the pleomorphic adenoma to have specificity of $98.2 \%$ and positive predictive value of $96.7 \%{ }^{6}$

Surgical excision is the appropriate therapy for pleomorphic adenoma of lacrimal gland. ${ }^{7}$ Excision of the mass with intact capsule is advised as the chance of recurrence within five years is $3 \%$ if the lesion is removed with an intact capsule and $30 \%$ if it is incompletely removed or the capsule is not intact. ${ }^{8} \mathrm{We}$ performed surgical excision of the mass through anterolateral transperiosteal orbitotomy with satisfactory outcome.

\section{ACKNOWLEDGEMENTS}

1. Dr. Santosh Chaudhary, Department of Ophthalmology, BPKIHS, Dharan, Nepal

2. Department of Radiology, B.P. Koirala Institute of Health Sciences, Dharan, Nepal.

\section{REFERENCES}

1. Weis E, Rootman J, Joly TJ, Berean KW, Al-Katan HM, Pasternak S, et al. Epithelial lacrimal gland tumors: pathologic classification and current understanding. Arch Ophthalmol 2009; 127(8): 1016-1028.

2. Wright JE, Stewart WB, Krohel GB. Clinical presentation and management of lacrimal gland tumors. Br J Ophthalmol 1979; 63: 600-06.

3. Ni C, Cheng SC, Dryja TP, Cheng TY. Lacrimal Gland tumors. International Ophthalmology Clinics 1982; 22: 99-120.

4. Kohli M, Shah A, Bhatt S, Aggarwal S. Lacrimal gland tumors - a retrospective histopathological study.Gujarat Medical Journal 2011; 66(1): 39-41.
5. Vagefi MR, Hong JE, Zwick OM, Bedrossian EH, Seiff SR, Cockerham KP. Atypical presentations of pleomorphic adenoma of the lacrimal gland. Ophthalmic Plastic and Reconstructive Surgery 2007; 23(4):272-274.

6. Verma K, Kapila K. Role of fine needle aspiration cytology in diagnosis of pleomorphic adenomas. Cytopathology 2002; 13:121-7.

7. Rose GE, Wright JE. Pleomorphic adenoma of the lacrimal gland. British journal of ophthalmology 1992; 76(7): 395-400.

8. Front RL, Gamel JW. Epithelial tumors of the lacrimal gland; an analyses of 265 cases. In: Jakobiec FA (ed). Ocular and adbnexaltumors .Aesculapis Publishing Co: Birmingham, Ala 1978; 787-805. 